\title{
Comunicación y sociedad brasileña: radio y cultura en debate
}

\author{
Antonio ADAMI \\ Universidade Paulista / UNICAMP (Brasil) \\ antonioadami@uol.com.br
}

\section{Resumen}

En este artículo se analiza la complejidad de la cultura y la radio brasileña, históricamente el gran mediador de la cultura. Como brasileños, viviendo en una región-continente, buscamos responder para nosotros y para el mundo "quien somos" y "qué queremos" para nuestro país. Vivimos en una sociedad de contraste, un mosaico cultural, donde la belleza de la naturaleza, la sonrisa de la gente, los positivos y nuevos caminos económicos son parte de la vida cotidiana de los brasileños que reacciona en convivir con el atraso político y por eso los conflictos y manifestaciones populares actuales.

Palabras clave: Comunicación y sociedad brasileña; Radio y Cultura brasileña; Radio y diversidad cultural.

\section{Communication and Brazilian society: radio and culture in debate}

\begin{abstract}
This paper analizes the complexity of the Brazilian radio and culture, historicaly considered the great mediator of the national culture. As Brazilians, living in a continent-region, we seek to respond to ourselves and the world "who we are" and "what we want" for our country. We live in a society of contrasts, a cultural mosaic where the beauty of nature, the smile of the people, the positive and new economy paths are part of the everyday lives of the Brazilian people who are reacting to the political backwardness, reason of the conflicts and current popular demonstrations.
\end{abstract}

Key Words: Communication and Brazilian society; Brazilian radio and culture; radio and cultural diversity.

Referencia normalizada:

Adami, A. (2013) Comunicación y sociedad brasileña: radio y cultura en debate. Historia y Comunicación Social. Vol. 18. Nº Especial Diciembre. Págs. 503-514.

Sumario: 1. Introducción. 2. Nace un nuevo medio. 3. Radio y cultura brasileña en la efervescencia de los años 1950-1960. 4. Comunicación, cultura y diversidad. 5. Conclusiones. 6. Referencias bibliográficas. 


\section{Introducción}

Proponemos este artículo enfocando inicialmente "el comienzo de un nuevo medio", donde se presenta el nacimiento de la radio en Sao Paulo y en Brasil, con el importante papel de la 'SQIG-Rádio Sociedade Educadora Paulista', 'PRA-8 Rádio Clube de Pernambuco' y 'Rádio Nacional de Rio de Janeiro'.

En un segundo momento tratamos de la Radio y la cultura brasileña en la efervescencia de los años 1950-1960, dialogando con los autores acerca de la realidad de aquellos días y la importancia de la radio en aquellos tiempos de grandes cambios en la vida de los ciudadanos del mundo, en particular en Brasil, un momento único en la historia, es decir, la gran circulación de dinero, industrialización, tecnologías de la comunicación y la información, los jóvenes ascendentes a las universidades, todo ocurriendo, cambiando efectivamente toda una sistemática de la lógica capitalista.

En tercer lugar, se analiza la radio, la cultura y la diversidad cultural, donde se abordan las cuestiones acerca de la importancia del medio y el conocimiento nacional de manifestaciones culturales y de la cultura popular brasileña. En esta sección, traemos las reflexiones de algunos autores importantes, que trabajan con estos campos de investigación y se centran en el papel de la radio como un mediador de la cultura y la diversidad cultural. Además, buscamos mientras se discute la comunicación como un campo de conocimiento y mediaciones en los diálogos de radio de la sociedad en su conjunto.

\section{Nace un nuevo medio}

Desde nuestra reflexión sobre el tema, la radio se abrió en la capital, Sao Paulo, en 30 de noviembre de 1923, cuando de la instalación de 'SQIG-Rádio Educadora Paulista', más tarde adquirida por la 'PRA-6 Rádio Gazeta', de propiedad del empresario Casper Libero. Sin embargo, el inicio oficial de la radiodifusión en Brasil se lleva a cabo en Río de Janeiro, en 7 de septiembre de 1922, en las celebraciones del Centenario de la Independencia. No es ni siquiera una radio como la conocemos hoy en día, pero es oficialmente la primera transmisión. En Río, sede del gobierno brasileño en dicha época, con potencia de 500 watts, la pionera 'Rádio Sociedade do Rio de Janeiro' abre sus micrófonos, de manera más regular, en abril de 1923. Aquel año fue realmente importante para la radio en Brasil. Por otra parte, la primera radio a hacer transmisiones radiofónicas (a pesar de no oficial) es realmente la 'PRA- 8 Rádio Clube de Pernambuco'. Inaugurada en 6 de abril de 1919, según Ivan Maurício, Igor Santos y Tiago dos Santos, del portal 'onordeste.com', la 'PRA-8' ya realizaba transmisiones radiofónicas en Brasil, aún experimentales, entre 1919 y 1923, y a partir de febrero de 1923, con 10 watts de potencia, pasa a ser captada en todo el centro de Recife. 
Realmente merecen destaque los pioneros 'pernambucanos' del radio, que rara vez se recuerdan de ellos en los estudios del campo y hicieron una admirable odisea radiofónico a finales de los años 1910. La 'PRA-8 Rádio Clube de Pernambuco', bajo la batuta de Antonio Joaquim Pereira, con colaboración de João Cardoso Alves Filho, Carlos Good Lacombe, Oscar Pinto Moreira y Carlos Lyra, obtienen el más antiguo registro conocido jurídico de la radiotelegrafía del país, de fecha 6 de abril 1919, con experiencias de radiofonía entre 1919 y 1921, pero oficialmente registrada como tal, en 17 de octubre de 1923.

La 'PRA-8' ya hacía transmisiones radiofónicas, muy artesanales, antes de 1922, sin embargo, lo que ha prevalecido es oficialmente la obra de Edgard Roquette-Pinto, otro grande e importante pionero, de Río de Janeiro. Acerca de la 'PRA-8', firman la siguiente información, el editor Ivan Mauricio y los directores Igor Santos y Tiago dos Santos, do galardonado portal 'onordeste.com'

Las primeras instalaciones funcionaron en el parque 'Treze de Maio'. En el inicio de los años 20, utilizando discos prestados, a 'Rádio Clube' transmitía operas, obras clásicas y recitales, que eran oídas a través de un radio receptor, construido artesanalmente y acompañado por auriculares. La instalación de un pequeño equipamiento de 10 watts, en febrero de 1923, permite que la 'Rádio Clube' sea sintonizada en el centro de Recife y en algunos barrios de la ciudad.

Sin embargo, la polémica no está solamente entre Río de Janeiro y Pernambuco, pero quien inicia la radio en Brasil y en el mundo, debidamente reconocida por científicos y estudiosos, es el sacerdote brasileño Roberto Landell de Moura, realmente predecesor de Marconi. En el libro de Ernani Fornari (1960), el autor escribe que Landell es el cuarto entre catorce hijos de Inácio José Ferreira de Moura e Sara Mariana Landell de Moura y cuenta su trayectoria.

\section{Radio y cultura brasileña en la efervescencia de los años 1950-1960}

Después de la inauguración de la radio en Brasil y en el mundo, que es, en general, entre los años 1920 a 1930, muchos cambios importantes se hicieron sentir en la vida social, política y económica, y se da cuenta de la capacidad del conglomerado de millones y por lo tanto, el uso político y comercial que proviene de esta característica. La radio proporcionaba una abertura de informaciones nunca visto en la historia. Por otra parte, también hubo una prisa enorme en la búsqueda del dominio de los nuevos medios y las nuevas tecnologías, sobre todo para la comunicación y el consumo de productos culturales. A partir de la radio, el surgimiento de la televisión, satélites, entre otros, que estaba muy cerca. Acerca de esta evolución de las tecnologías de los medios y de las tecnologías de comunicación, según Maigret (2010. Pág. 188-189), la segunda mitad del siglo XX, destrona la máxima de que los medios de comunicación se sustituye simplemente, de acuerdo con las nuevas tecnologías y la eminencia de otros medios, o que los espectadores sólo reciben pasivamente lo que se publica. Los 
debates de los años 1950-1960 se dan cuenta de que la cultura contemporánea se relaciona con los medios de comunicación y el poder, y estos medios no se sustituyen, sino simplemente se adaptan, se integran, se complementan. De hecho, hoy en día, es difícil darse cuenta de los límites de uno y otro campo, pero sin duda, la cultura es el sesgo que da sentido a la sociedad. Escribe Brant (2005. Pág. 13-14):

En estos nuevos tiempos, qué está en disputa es la corrida por la más estrecha de las especiarías, la cultura, que viene embalada en sus innumerables y diversificadas manifestaciones (...) pero qué da gracia a la vida es la cultura. Y qué da gracia a la cultura es la diversidad. La moneda de más alto valor en el mercado global tiene la cultura en una de sus caras y la diversidad en otra. El enorme valor agregado por los dos lados de esa moneda solo tiene a crecer en todos los comercios. Es una inversión segura en la bolsa de valores de la vida.

Realmente la década de 1960 ha traído grandes cambios políticos, económicos y culturales, $\mathrm{y}$, las discusiones sobre cultura que derivan de estos cambios, que están vinculados, por ejemplo, a la amplia difusión de las tecnologías, industrialización, comunicación y información, los jóvenes ascienden a las universidades, cambian efectivamente toda una lógica capitalista sistemática, porque hay un nuevo invento de la vida, más cercana de estas tecnologías y los nuevos ritmos y procesos culturales, que apunta a cambios importantes. Estas nuevas tecnologías están emergiendo a una velocidad vertiginosa, cambian la forma de producir, recibir y percibir la información, el arte, el cine, la literatura, la música. Desde la década de 1960, no hay nada igual en el mundo, ya que los jóvenes que tuvieron acceso a las transformaciones de los años 1950, 1960 y 1970, en busca de su parte, en este sentido, las universidades y los medios de comunicación son la clave. En aquel momento, la comunicación mediática camina para su apogeo y la radio es un actor muy importante en esta ruta. Una nueva cultura estalla en 1960, de una cultura de desafío en la búsqueda de una mayor distribución de los bienes, más trabajo, salud, vivienda, búsqueda de mejores condiciones sociales, que hasta entonces había estado envuelto por un manto de diferentes sectores, incluidas las universidades, de sectores de la producción, de las élites y parte del clero. A partir de ahí, con el avance de las tecnologías de la información y la comunicación, el campo de la cultura empieza a convertirse en un foco, con todos estos nuevos actores sociales. En este período y en los años siguientes, América Latina sufre las dictaduras de todo tipo, blanco, rojo, azul, verde y amarillo, y, a saltos agigantados llega en 2013 al mundo global, este mundo aparentemente integrado, pero con mayores y más resistentes fronteras; con las tasas de mortalidad infantil más altas de la historia; el hambre llamando a la puerta de millones de personas en todos los continentes y el desempleo abrumador, haciendo estragos en todos los continentes. Se puede observar que el pico de las tecnologías de comunicación sólo sirve al sistema financiero y a los principales grupos empresariales. Tratando del tema, Milton Santos (2006), analiza la globalización en tres categorías: 'como fábula, como realmente es y cómo podría ser, es decir, otra globalización:

Los fundamentos del mundo de hoy son la información y su imperio, que son la base para la producción de imágenes y del imaginario, y se ponen al 
servicio del imperio del dinero, en base a esta economía y la monetización de la vida social y personal.

Brasil también convive con esta efervescencia de los años 1950 y 1960, sólo, mientras que los EE.UU. y Europa se desarrollan, desde el punto de vista de la participación social y política y las cuestiones culturales, en América Latina se ha aislado y se encuentra en el centro de los intereses de Estados Unidos, que impone dictaduras militares y castran toda una generación de artistas, periodistas, escritores, políticos, cineastas, investigadores, etc., y, en ese sentido, hemos perdido el tren "de la historia". Nos vemos obligados a vivir y consumir producción cultural y ideológica norteamericana. Un retraso de décadas y un foso creativo, político y cultural que se extiende entre América Latina y otros países desarrollados. Estas cuestiones parecen anticuadas ahora, si pensamos en un mundo global y el acceso rápido a casi todo, pero nos damos cuenta de que el acceso a la información sólo es editado y, por lo tanto, este mundo global, no puede disminuir el atraso social, articulado, por desgracia, con el pensamiento neoliberal, que viene del Consenso de Washington ${ }^{1}$, que, a raíz de las reflexiones de Milton Santos, parece una pesadilla para perseguir América Latina y otras regiones, hoy llamado eufemísticamente como emergente, pero que parece almas perdidas tanteando en la oscuridad y a la misericordia de los imperios de comunicación y del sistema financiero internacional.

Presentamos esta breve reflexión porque cuando se analizan los medios de comunicación y la cultura, estas discusiones son la propia orden del día. Pensar el papel de los medios de comunicación también es discutir su historia y la función política que ejercen junto a la sociedad en su conjunto. En Brasil, a pesar de pasar terribles dictaduras, las décadas 1950 a 1980, por otro lado, traen también transformaciones en el ámbito de la cultura, de la política, del arte, de la comunicación, con una explosión de la cultura popular. El Brasil rural, de comunidades campesinas, que van a convivir con un Brasil cada vez más urbanizada e industrializada, especialmente desde finales de los años 50. En este período, la cultura de la élite tradicional, heredada del siglo XIX, comienza a convivir con los nuevos medios y lenguajes artístico-culturales modernos y cosmopolitas.

Por lo tanto, la producción radiofónica es fundamental para los cambios culturales, políticos y comunicacionales que se avistaba. La radio en Brasil es el medio que puede mover las masas, llevar y traer la información, arte y cultura a los rincones más lejanos. Un ejemplo llamativo es que uno de los músicos regionales más importantes

1 El Consenso de Washington, en la verdad, es base del neoliberalismo. En 1989 Washington convoca, por el Institute for International Economics, diversos economistas de Latino América de perfil liberal, funcionarios del Fondo Monetario Internacional (FMI), Banco Mundial y Banco Interamericano de Desenvolvimento (BID) y el gobierno norteamericano, para evaluar las reformas económicas en curso en Latino América. John Willianson, fue quien esbozó los diez puntos, que irían nuevamente llevar los países a una dependencia y al retraso social y cultural histórico, como niños delante de dulces. Ledo error! 
del país, Luiz Gonzaga, el rey de "Baião2", sólo es conocido en Sao Paulo y en el sur de Brasil, a partir de las ondas de la radio.

São Paulo y Rio de Janeiro, de hecho, desde la década de 1920, pero sobre todo en la década de 1930, se convierten en los principales centros de formación de radio-actores, comediantes, radio-periodistas y a producir diferentes géneros radiofónicos. Estos profesionales terminan llevando este conocimiento a otras regiones, especialmente al Norte y Nordeste, y empiezan a influir en estas regiones. Pero no sólo Sao Paulo y Río se estructuran como grandes centros de radio, también Minas Gerais, Rio Grande do Sul, Pernambuco, Bahia, siguen la misma línea, con el elenco de grandes nombres del cast nacional. También no solo las capitales tenían ese poderío, tenía también ciudades del interior y de los litorales brasileños. Ilustrando este discurso, en seguida presentamos la lista oficial del año 1936, la década de mayor explosión de estaciones de radio en Sao Paulo y de Brasil, con la "Relación de Estaciones Brasileñas de Radiodifusión", lista del "Ministério da Viação e Obras Públicas", institución ésta responsable en aquel momento por la radiodifusión, qué hoy pertenece al Ministerio de las Comunicaciones.

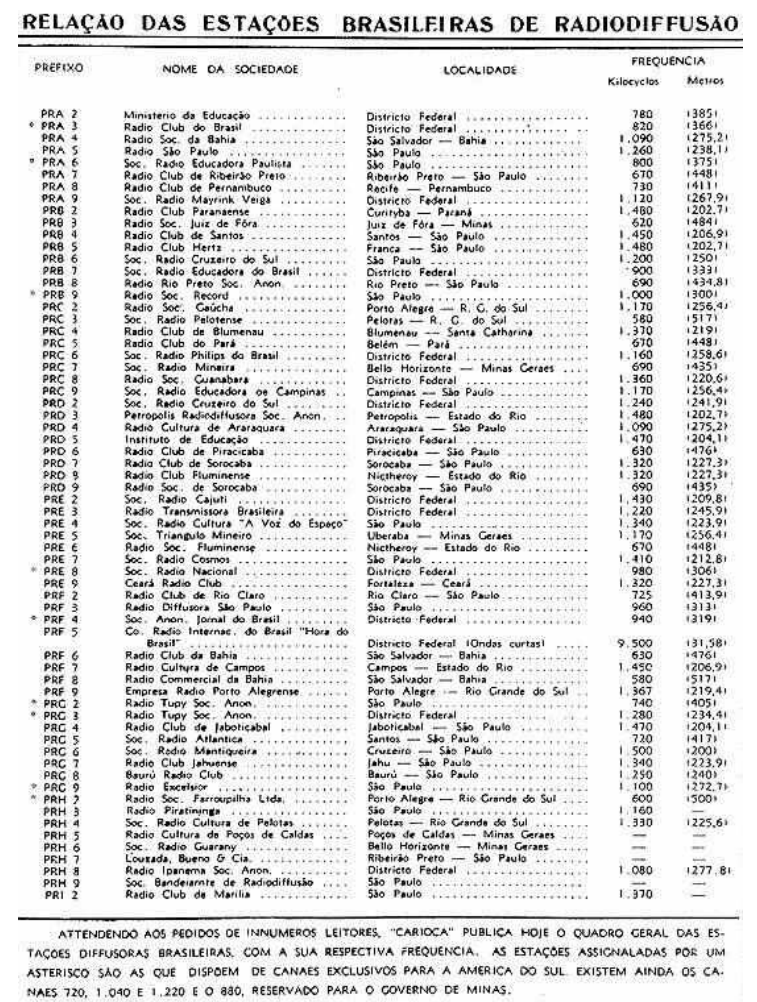

Copia del listagen publicada por la revista 'Carioca', en 19/set./1936, digitalizada, de acuerdo con Tincani (2005), por el investigador Geraldo José Santiago.

2 Un ritmo de canción y danza muy popular en las regiones Nordeste y Norte de Brasil. 


\section{Comunicación, cultura y diversidad}

La experiencia del Padre Landell de Moura y los "caminos" que la radio tuvo hasta convertirse en el principal medio de comunicación de masas conocido, nos damos cuenta de que siempre es complicado analizar la cultura, pues la cultura es algo tan intangible, tan caro y arriesgado para conceptualizar, tan sencillo y sofisticado al mismo tiempo, que podemos perdernos en los caminos de la abstracción, e incluso en la casuística pasión nacionalista y olvidar su propia cultura, el sentimiento de pertenecer a una región, una parte del mundo, construir relaciones, tener una identidad y una fisionomía. También podemos perderse en la telaraña teórica de la cultura, lejos de nuestra propia historia, de la pulsación de lo que está sucediendo en las calles, en los edificios, en los supermercados, playas y plazas, en las granjas, ferias, en el día a día de los ciudadanos comunes y también del ciudadano que no es tan común. En este sentido, la radio es el medio que supe incorporar las masas, hablar con la gente. Tratando así de entender un poco más de las raíces de la cultura popular y la radio, que se encuentran en la música popular brasileña - música esta que se extiende y se conoce en Brasil a partir de la llegada de la radio -, y en la línea de investigación denominada "nacionalismo en la cultura", algunas análisis interesantes. Sobre el tema, escriben Squeff y Wisnik (2004, p. 88-89),

Para los nacionalistas, el pueblo sería objeto numero uno de sus preocupaciones; ni tanto en aquello que el pueblo tenía de ser, idealmente, en una sociedad industrializada, pero en aquello que él era incluso en su miseria, en su sub desarrollo. (...) El arte nacionalista nunca dejó de atraer. Sea porque pone con alguna coherencia la necesidad de inspirarse en el popular, sea porque tiene a la mano en los elementos que puede utilizar para denunciar algunas maculas.

Pero, en nuestro opinión, una de las reflexiones más interesantes sobre el tema no vino de los sociólogos, de comunicólogos, antropólogos, ni de historiadores, sino de un músico, enamorado de la cultura brasileña. Escribe Gilberto Gil (2005. Pág. 10-11):

Hoy, como ministro de la Cultura de mí país ${ }^{3}$, veo en el concepto de cultura la posibilidad de manejar con el Ser brasileño en todas sus dimensiones, sumergido en un medio ambiente Brasil que siempre es naturaleza y cultura. Como uno artista y ciudadano del mundo, veo en la cultura el espacio para el encuentro de países, credos, etnias, sexualidades y valores, en la cacofonía de sus diferencias, en el antagonismo de sus incompatibilidades, en generosidad de un lugar común, algo que nunca existió, pero siempre fue soñado por aquellos que dejan su mirada perderse en el horizonte.

Apenas para elucidar, cuando Gilberto Gil habla de horizonte, segundo él propio, en 'Diversidade Cultural' (2005, p. 7-11), se reporta a su infancia, en la ciudad de Salvador - capital de Bahia, donde nació, en 26 de junio de 1942, observando el mar, con los ojos en el horizonte.

3 Gilberto Gil fue ministro de Cultura del gobierno Lula (2003-2008). 
Desde el punto de vista de la expresión artística, la radio es también el gran mediador de la cultura popular y la cultura regional. Es por la radio que conocemos diferentes manifestaciones artísticas y culturales, que a menudo sólo se producen local y regionalmente, no llegando a los medios de comunicación nacionales. Estas expresiones artísticas, sea música, danza, folclore, tan rica en este gigante país, plural y mestizado, no tienen espacio en la grande media, pero encuentra en la radio una manera de hacerse oír. Sobre diversidad Cultural, escribe Brant (2005):

Como la realidad, la cultura es una, pero sus manifestaciones son múltiples. Sólo la diversidad nos une, susurra el planeta. Ni en todo es harina del mismo bolso, como gustaría de nos hacer creer los que quieren imponer al mundo sus valores culturales particulares. La cultura es una como la lluvia que caya sobre todos los campos del planeta; y florece amarilla y blanca en la margarita, rosa en la rosa y azul en la flor de arasá.

En la verdad, la radio y la cultura, particularmente la cultura popular, tiene una relación de complicidad histórica. La radio reflete la cultura brasileña, como fenómeno que es, o sea, al mismo tiempo notable, intrigante y contradictoria, pues históricamente nos relacionamos con la cultura de los indios, negros, de los blancos portugueses, italianos, españoles, la cultura de élite, cultura de la clase obrera, la cultura de mestizaje, cultura del litoral, de capitales urbanas, la cultura política, ésta, con un pasado y un presente que siempre nos sorprende por la falta de ética y por una corta visión social. De todos modos, vivimos en un país-continente de contradicciones, de diversas culturas en conflicto, un mosaico cultural. En este sentido, escribe Napolitano (2006):

Analizar la cultura brasileña es, ante todo, un rompecabezas que nos persigue desde que nos convertimos en una nación independiente. La cuestión de la cultura nacional está vinculada a la necesidad de responder a nosotros mismos y al mundo "lo que somos" y "lo que queremos" para nuestro país. Las respuestas no pueden ser únicas en una sociedad tan dividida, en contraste y en conflicto como la brasileña, es un mosaico cultural. Nuestra mirada a la cultura no es algo aburrido e inerte, entendida sólo a través de conceptos teóricos, ya que puede aislar a la cultura de una realidad social más amplia. Decidimos entonces por una perspectiva que pretende dar a conocer la cultura brasileña como un ser vivo, dinámico, escurridizo y inserida en la realidad de todos nosotros, los ciudadanos en busca de una identidad. No puede ser clasificado de manera objetiva y fría en que es el caleidoscopio del país, en sí mismo, contradictorio, dinámico y plural.

Cuando tratamos de estudios científicos acerca de Comunicación y Cultura, creemos importante sublimar que estos se establecen en la segunda mitad del siglo XX, en el contexto de los cambios sociales, educativos, políticos, de los golpes militares, dictaduras, mediadas y traducidas por los medios de comunicación, especialmente la radio y luego la televisión. De hecho, para el ámbito de la comunicación, la cultura es un objeto de investigación normalmente relacionado con los medios, así como para la historia el principal sesgo es la fuente. No es raro encontrar lecturas de investigadores de áreas afines y incluso de comunicación, analizando esta como parte de la sociología o, la semiótica como ocupante de un lugar intermedio en la historia de las teorías 
de la comunicación. El sociólogo Éric Maigret (2010), denota una posición bastante propia sobre la discusión:

Comunicar es antes de todo participar de una cultura, constituyendo en última instancia de un hecho político. Ciertamente la técnica o tecnología viene después. Así, surge un triangulo de fuerza bastante evidente relacionado a la comunicación: cultura-política-tecnología, mientras la tecnología sea en si un hecho cultural (...) Los medios de comunicación son, en la verdad, la marca registrada de nuestra época y constituyen la afirmación de las sociedades democráticas. Ellos tornan posible por medio de los textos cambiados, de las imágenes disponibles y de los sonidos transmitidos - un intercambio rápido y permanente entre los diferentes pueblos y culturas.

Obviamente, el área de la comunicación no se realiza sólo por los medios de comunicación, ni sólo es la sociología quien realmente produce los modelos de interpretación de textos u obras audiovisuales, especialmente en estos días que permiten el acceso a una red de información gigantesca, operada por grupos empresariales y por un sistema financiero no menos gigantesco. Teniendo en cuenta estas discusiones, la mirada para la comunicación y la cultura parece una opción muy gigante en la comprensión de la sociedad contemporánea.

En este sentido, el medio radio surge en los años 1920, y hasta hoy en Brasil, es un vector de la cultura popular, como medio de comunicación de masa irradiando para diferentes públicos, en diferentes regiones, a veces tratase de un público local, otras veces en también nacional o global. Además es la lógica actual de los medios, donde la comunicación, sin duda, históricamente, es regida por la tecnología y por el conocimiento de las técnicas, sentido tan bien explorado por Milton Santos, ya citado arriba.

El papel de la radio en la cultura brasileña, desde la década de 1920, ciertamente es el gran mediador y también es un medio poderoso para mediar la diversidad cultural. Resaltamos que este fenómeno no sólo se produce a partir de la década de 1920, pero hasta los días de hoy, pues el advenimiento de la televisión en Brasil - la primera emisión es el 18 de septiembre de 1950 - no cambia el panorama dado, entre otras cuestiones, por el hecho de que estamos en un país-continente y también porque llevamos en nuestra cultura la formación de escuchar la radio. Es común que la gente asista a partidos de fútbol en los estadios, escuchando un radio de batería 'a los pies de la oreja'. Además, la radio también es compañero y tiene importantes funciones sociales, especialmente en las zonas fronterizas con otros países. En muchas ocasiones estos residentes utilizan la radio local para comunicarse con vecinos, con las autoridades, para conocer una campaña de salud pública, por ejemplo. Esto ocurre porque estas regiones reciben la programación de televisión de la matriz, en la capital, pues no hay ninguna programación local, además, no es un medio adecuado para este tipo de comunicación. La radio es aún más apropiada, por su agilidad, la capacidad de trabajar en tiempo real y con un costo muy bajo en comparación con otros medios de comunicación. La internet funciona mal en estos casos porque además de no tener una cultura local de esta tecnología para la comunicación regional, estas ciudades son 
litorales, básicamente rurales, o ribeirinhas con una fuerte conexión con la naturaleza y no denotan gran interés en "ordenadores". En estos casos, la función de la radio es única y extremamente importante, pues, además de campañas públicas en locales más inhóspitos, como vimos arriba, también cuando ocurre incendio forestal, cuando hay epidemias o inundaciones, aislando comunidades y ciudades enteras. De hecho, cada año inundaciones devastan parte del sur de Brasil y, en estos casos, es necesario la comunicación urgente y contacto eficaz con las comunidades locales. En estos momentos es que las radios comunitarias ${ }^{4}$ son eficaces. En estas condiciones, que normalmente se producen en las regiones más alejadas de los principales centros del país, la radio es esencial como un integrador y un agente social. Las radios comunitarias, por ejemplo, en estos casos particulares y de excepción, ejercen un importante papel social en las comunidades donde están instaladas, especialmente por identificarse con un grupo social y vivenciar los problemas locales. Segundo Vitor (2009):

Tales radios presentan diversas ventajas para la población local, desde la información, educación informal, su cultura propia, participación activa de las personas de comunidad y de representantes de movimientos sociales y otras formas de organización colectiva en la programación, de los procesos de creación y planeamiento hasta la gestión de emisora. Una característica importante de esas radios es el ejercicio de ciudadanía, representando un canal abierto a la libertad de expresión, independientemente de sus convicciones políticas, credos religiosos, escolaridad, cualidad de voz etcétera.

Históricamente, en Brasil, la radio comunitaria tiene sido expresión de población empobrecida que, por medio de sus organizaciones sociales, desarrolla trabajo de información, educación informal, desarrollo cultural y movilización de personas visando mejorías en las condiciones de existencia. En su proceso de acción, en general conectado a las luchas sociales más amplias en cada lugar, la emisora comunitaria tiene a contribuir para la movilización social y trabajo organizativo local con intuito de mejorar servicios públicos, desarrollar trabajos educativos contra violencia, propagar productos artísticos de miembros de la 'comunidad', además de desencadenar posibilidades de educación informal y no formal.

\section{Consideraciones}

Por el espacio de este artículo, concluimos en el nuestro, con nuevas cuestiones, proponiendo nuevos desafíos a partir de las reflexiones realizadas, o sea: ¿Los medios de comunicación tienen respondido a altura qué se espera de ellos con relación a la cultura y a diversidad cultural brasileña? ¿Cuál papel tiene el radio y los medios de

4 Las radios comunitarias sirven como un modelo particular de comunicación, diferente de la media convencional. Las radios comunitarias contribuyen para el desarrollo cultural y social de comunidades locales. De acuerdo con Lei no 9.612, de 19 de febrero de 1998 "denominase Servicio de Radiodifusión Comunitaria la radiodifusión sonora, en frecuencia modulada, operada con potencia limitada a 25 watts y cobertura restrita, otorgada las fundaciones y asociaciones comunitarias, sin fines lucrativos, con sede en la localidad de prestación del servicio". 
comunicación en la cultura? ¿Y el estudio de la historia de los medios, particularmente el radio, como se vincula a las teorías clásicas y actuales de comunicación?

\section{Referencias bibliográficas}

ADAMI, ANTONIO; SANDE, MANUEL FERNANDEZ (Coords.) (2012). Panorámica de los medios de comunicación Brasil-Espanha. São Paulo: E-Livros Intercom.

ALMEIDA, HAMILTON BENEDITO (1983). O outro lado das telecomunicações A saga do Padre Landell. Porto Alegre: Editora Sulina.

BARBERO, JESÚS-MARTÍN (2003). Dos meios às mediações. Rio de Janeiro: Editora da UFRJ.

BARROS, JOSÉ MÁRCIO (Coord.) (2008). Diversidade Cultural - da proteção à promoção. Belo Horizonte: Autêntica Editora.

BRANT, LEONARDO (Coord.) (2005). Diversidade Cultural. São Paulo: Instituto Pensarte.

FORNARI, ERNANI (1960). O Incrível padre Landell de Moura - O Brasileiro precursor das Telecomunicações. Rio de Janeiro: Editora Globo.

GIL, GILBERTO (2005). Do conhecimento à sabedoria. En: BRANT, LEONARDO (Coord.) (2005). Diversidade Cultural. São Paulo: Instituto Pensarte.

MAIGRET, ÉRIC (2010). Sociologia da comunicação e das mídias. São Paulo: Editora SENAC.

MARANHÃO FILHO, LUIZ BELTRÃO (2011). As origens do rádio.

MARTINS, MOISÉS DE LEMOS (2011). Crise no Castelo da Cultura. São Paulo: Annablume.

MAURÍCIO, IVAN; SANTOS, IGOR E SANTOS, TIAGO DOS. Enciclopédia Nordeste Rádio Clube de Pernambuco (online). Disponible en: http://www.onordeste.com/onordeste/enciclopediaNordeste/index.php?titulo $=\mathrm{R} \% \mathrm{C} 3 \% \mathrm{~A} 1 \mathrm{dio}+-$ Clube + de + Pernambuco\&ltr $=$ R\&id perso=782. Aceso: [15-10-2013].

MELO, JOSÉ MARQUES DE (2008). Mídia e Cultura Popular. São Paulo: Paulus. NAPOLITANO, MARCOS (2006). Cultura Brasileira - Utopia e massificação. S. Paulo: Contexto.

SANTOS, MILTON (2006). Por uma outra globalização. Rio de Janeiro: Record.

SKEFF, ENIO; WISNIK, JOSÉ MIGUEL (2004). O nacional e o popular na cultura brasileira. São Paulo: Brasiliense.

TINCANI, DANIELA (2005). PRA-7 A estação do coração de São Paulo. Disertación de máster, Sao Paulo: UNIP.

VITOR, SARA LEMES PERENTI [12-10-2009]. O papel social das rádios comunitárias. Disponible en: www.observatoriodaimprensa.com.br. Aceso: [15-102013].

Sites

http://www.planalto.gov.br/ccivil_03/leis/19612.htm. Aceso [02-09-2013]. 


\section{El autor}

Antonioo Adami é doutor pela FFLCH-USP; fundador e professor titular do Programa de Pós-Graduação em Comunicação da Universidade Paulista; professor convidado do Programa de Doctorado en Periodismo de la Facultad de Ciencias de la Información de la Universidad Complutense de Madrid; professor em caráter temporal do Departamento de Midialogia da Unicamp; pesquisador do Grupo "Mídia, Cultura e Memória" junto ao CNPq, no Brasil, e do Grupo "MEDIACOM UCM", junto à Complutense de Madrid. 